\title{
The role of $M R I$ in evaluation of fetal urinary tract anomalies with normal and abnormal volume amniotic fluid
}

\begin{abstract}
Purpose: to evaluate the role of magnetic resonance imaging (MRI) in evaluation of fetal urinary abnormalities with normal and abnormal volume amniotic fluid after ultrasound examination.

Methods: The prospective study from April 25, 2016 to January 21, 2017, comprised 16 fetuses with normal volume amniotic fluid 10 patients and abnormal volume amniotic fluid (an/oligohydramnios) 6 patients. All fetuses with suspected congenital urinary tract anomalies based on ultrasound underwent MRI examination with $1.5 \mathrm{~T}$ and $3 \mathrm{~T}$ MRI. The MRI findings were compared to ultrasound, micturition urethrocystography (MUC), computed tomography (CT) and magnetic resonance imaging (MRI) findings as a gold standard postpartum imaging and surgical findings. Gestational age range was $19-37$ weeks.

Results: In anhydramnios 2 fetuses showed concordant with MRI (bilateral multicystic dysplatic kidney (MCDK) and normal kidney), 1 fetus with hypoplasia kidney between ultrasound (US) and MRI is discordance, in oligohydramnios 3 fetuses MRI has additional information (autosome recessive polycystic kidney dysplasia (ARPKD) with fibrocystic liver, anterior urethral valve and posterior urethral valve obstruction). In normal amniotic fluid MRI gave additional information in 9 patients (left hydronephrosis (HN), prune belly syndrome, vesicourinary junction obstruction (VUJO) bilateral, megacystis microcolon intestinal hypoperistaltic syndrome (MMIH), cloaca, Left multicystic dysplastic kidney (MCDK), L pelvic cyst and horseshoe kidney), 1 patients showed concordant with MRI (L pelviuretero junction obstruction (PUJO)).
\end{abstract}

Conclusion: Fetal MRI can be used as a complementary toll in evaluation of fetal urinary tract anomalies with normal and abnormal volume amniotic fluid cases.

Keywords: fetal MRI, congenital urinary tract anomalies, normal and abnormal volume amniotic fluid.

\author{
Volume 4 Issue 5 - 2017
}

\author{
Dewi Asih Wirasasmita, ' Yarmaniani Miliati \\ Muchtar, ${ }^{2}$ Gatot Abdurrazak, ${ }^{3}$ Sadina \\ Pramukti Besar ${ }^{3}$ \\ 'Department of Radiology, Premier Jatinegara Hospital, Jakarta, \\ Indonesia \\ ${ }^{2}$ Department of Radiology, Harapan Kita Women and Children \\ Hospital, Indonesia \\ ${ }^{3}$ Department of Obstetrics and Gynecology, Harapan Kita \\ Women and Children Hospital, Indonesia
}

Correspondence: Dewi Asih Wirasasmita, Department of Radiology, Premier Jatinegara Hospital, Jakarta, Indonesia, Email dewi_wirasasmita@yahoo.com

Received: October 14, 2017 | Published: November 16, 2017
Abbreviations: MRI, magnetic resonance imaging; MUC, micturition urethrocystography; CT, computed tomography; MCDK, multicystic dysplatic kidney; ARPKD, autosome recessive polycystic kidney dysplasia; HN, hydronephrosis; VUJO, vesicourinary junction obstruction;mmIH, megacystis microcolon intestinal hypoperistaltic; MCDK, multicystic dysplastic kidney; PUJO, pelviuretero junction obstruction; FOV, field of view

\section{Introduction}

Congenital urinary tract anomalies are relatively common, accounting $\pm 30-50 \%$ of all structural anomalies at birth. ${ }^{1}$ The abnormalities are broad spectrum from mild to severe which is threatened of fetus. US is still using for screening urinary tract anomalies. ${ }^{2,3}$ Some conditions such as anhydramnios and oligohydramnios, the results may be inconclusive. In these situations the organ cannot be evaluated sufficiently. It is a clearly indication to performed fetal MRI for urinary tract anomalies. ${ }^{4-8}$ Otherwise in normal volume amniotic fluid urinary tract can be seen clearly by US. MRI has large field of view and good natural contrast can differentiate between dilated urinary tract and bowel and also determine level obstruction. The purpose of this paper is to evaluate the role of MRI in urinary tract anomalies with normal and abnormal volume amniotic fluid.

\section{Materials and methods}

We prospective examine 19 fetuses from April 25, 2016 to January 21, 2017 with suspected urinary tract anomalies based on ultrasound. Inclusion criteria presence of oligohydramnios or anhydramnios, and normal amniotic fluid with abnormal urinary tract or multisystem anomalies with improper visualization of kidney. MRI was done within 1weeks following US. Three mothers of fetuses with contraindication to MRI and claustrophobia were excluded. Sonography was performed by obstetrician using Samsung A30, full 2D combined gray scale and color Doppler studies and 3D, 3,5-5MHz. Amount of amniotic fluid using 4 quadrant amniotic fluid index. Color Doppler was done to search renal arteries in suspected renal agenesis.

MRI was performed with 1.5T siemens avanto, Erlanger, Germany, 1.5T GE, signa HDe, and Siemen skyra 3T, using body coil with supine or LLD position. After a scout acquisition, a series of fetal images in axial, sagittal and coronal T2HASTE/FFSFE with $4 \mathrm{~mm}$ slice thickness and $30-35 \mathrm{~cm}$ FOV and sagittal T1SPGR, heavily T2W MRU with 
$50 \mathrm{~mm}$ slice thickness, axial DWI b value 700. Contrast agent and sedation were not used. All MRI were analyzed by radiologists who experienced in fetal MRI who was blinded to US results. Amniotic fluid was qualitatively assessed as normal or diminished on the bases of the ability to identify at least three large pockets of fluid with a depth greater than $2 \mathrm{~cm}$. Informed consent was obtained from all the mothers. Follow up was done for 10 fetuses with ultrasonography and contrast study (cystogram, retrograde pyelography, cloacagram), surgical exploration and CT, 6 fetuses were fetal demise and refused autopsy.

\section{Results}

Gestational age ranged from 19 to 35 eeks. Fetal movement did not alter image quality. We divided into 2 groups of patient between an/ oligohydramnios (Table 1) and normal amniotic fluid (Table 2). In an/ oligohydramnios diagnosis ultrasound revealed concordant with MRI $2 / 6(33,3 \%)$ fetuses, $3 / 6(50 \%)$ MRI gives additional information, $1 / 6(16,6 \%)$ discordant (hypoplasia kidney). In discordant case USG revealed hypoplasia but fetal MRI result agenesis. MRI was performed in 21 weeks gestation whereas intensity of kidney is similar with small bowel. Ultrasonography with color Doppler flow easier to visualize renal artery so more accurate to determine agenesis kidney. According to previous journal MRI is to be useful adjunct to US for the diagnosis agenesis kidney. ${ }^{5,9,10}$ In this case MRI had no significant advantage over US unfortunately the parent refused autopsy (Figure 1). In case ARPKD US is sufficient to see enlargement of the kidney with hyperechoic in medullary kidney and fibrocystic liver (Figure 2), MRI has additional information for looking maturity of the lung. With increasing gestational age the intensity of the lung will increase as well. ${ }^{11,12}$ In this case fetal MRI examination was performed in 35 weeks of gestation, but the lung intensity is still hypointens. Anoligohydramnios prevent growth thoracic cavity therefore maturity of the lung is inhibited which is cannot be seen by US. One case with bilateral hydrouretronephrosis and megacystic based on US, MRI gives additional information a cystic lesion on left kidney. Other case with hydrouretronephrosis and megacystis confirmed by MRI, MRI has additional information dilatation anterior urethra (Figure 3) was proven by MUC (Figure 4). One case with anhydramnios but normal both of kidney the result of US is the same with fetal MRI. The cause anhydramnios is premature rupture of the membrane.

Table I An/oligohydramnios

\begin{tabular}{|c|c|c|}
\hline USG & MRI & Confirmation \\
\hline $\begin{array}{l}\text { Bilateral Renal } \\
\text { Hypoplasia }\end{array}$ & Bilateral Renal Agenesis & Stillbirth \\
\hline Bilateral MCDK & Bilateral MCDK & Stillbirth \\
\hline $\begin{array}{l}\text { Bilateral ARPKD, } \\
\text { Fibrocystic Liver }\end{array}$ & $\begin{array}{l}\text { Bilateral ARPKD, Fibrocystic } \\
\text { Liver, Hypoplasia Lung }\end{array}$ & Stillbirth \\
\hline $\begin{array}{l}\text { HUN Bilateral, } \\
\text { Megacystis }\end{array}$ & $\begin{array}{l}\text { HUN Bilateral, Renal Cyst } \\
\text { RK, Megacystis, }\end{array}$ & US, MUC \\
\hline $\begin{array}{l}\text { Normal Bilateral } \\
\text { Kidney }\end{array}$ & Normal Bilateral Kidney & Stillbirth \\
\hline $\begin{array}{l}\text { HUN Bilateral, } \\
\text { Megacystis }\end{array}$ & $\begin{array}{l}\text { HUN Bilateral, Megacystis, } \\
\text { Hydrourethra }\end{array}$ & MUC \\
\hline
\end{tabular}

Table 2 Normal amniotic fluid

\begin{tabular}{|c|c|c|c|}
\hline USG & MRI & $\begin{array}{l}\text { Method } \\
\text { Confirmation }\end{array}$ & $\begin{array}{l}\text { Final } \\
\text { Diagnosis }\end{array}$ \\
\hline LHN & LHUN & MUC, USG & VUJO \\
\hline HN bilateral & $\begin{array}{l}\text { Bilateral HUN } \\
\text { Dominant on the } \\
\text { Left Side }\end{array}$ & $\begin{array}{l}\text { RPG at the Left } \\
\text { Side }\end{array}$ & $\begin{array}{l}\text { VUJO Left } \\
\text { Side }\end{array}$ \\
\hline $\begin{array}{l}\text { Megacystis, } \\
\text { Multiple Renal } \\
\text { Cysts }\end{array}$ & $\begin{array}{l}\text { Megacystis, } \\
\text { Bilateral HUN, } \\
\text { Cryptorchidism }\end{array}$ & $\begin{array}{l}\text { MUC, Physical } \\
\text { Examination }\end{array}$ & $\begin{array}{l}\text { Prune Belly } \\
\text { Syndrome }\end{array}$ \\
\hline $\begin{array}{l}\text { Megacystis, } \\
\text { Keyhole }\end{array}$ & $\begin{array}{l}\text { Megacystis, gastric } \\
\text { dilatation, no } \\
\text { meconium in large } \\
\text { bowl, no keyhole }\end{array}$ & laparotomy & MMIH \\
\hline $\begin{array}{l}\text { bilateral } \\
\text { HN, Ascites, } \\
\text { Multiple Pelvic } \\
\text { Cysts }\end{array}$ & $\begin{array}{l}\text { bilateral HUN, } \\
\text { Hydrometrocolpos, } \\
\text { Ascites, Abnormal } \\
\text { Rectum Position }\end{array}$ & $\begin{array}{l}\text { Cloacagram, } \\
\text { Laparotomy }\end{array}$ & $\begin{array}{l}\text { Cloaca } \\
\text { Malformation }\end{array}$ \\
\hline LHN & LHN & US & PUJO \\
\hline $\begin{array}{l}\text { Agenesis LK, } \\
\text { Multiple Pelvic } \\
\text { Cyst }\end{array}$ & $\begin{array}{l}\text { MCDK LK, no } \\
\text { Pelvic Cyst }\end{array}$ & MRI & MCDK \\
\hline $\begin{array}{l}\text { Megacystis, } \\
\text { HUN Bilateral }\end{array}$ & $\begin{array}{l}\text { HN RK, HUN LK } \\
\text { with Ureterocele } \\
\text { and Cystic } \\
\text { Dysplastic, No } \\
\text { Bladder }\end{array}$ & N/A (stillbirth) & \\
\hline L Renal Cyst & $\begin{array}{l}\text { L Pelvic Cyst with } \\
\text { Calyceal Dilatation }\end{array}$ & USG & L Pelvic Cyst \\
\hline $\begin{array}{l}\text { Multiple } \\
\text { Congenital }\end{array}$ & & & \\
\hline $\begin{array}{l}\text { Anomalies, } \\
\text { Improper } \\
\text { Visualization of } \\
\text { Kidney }\end{array}$ & $\begin{array}{l}\text { Horseshoe Kidney } \\
\text { with L HN }\end{array}$ & USG, CT & $\begin{array}{l}\text { Horseshoe } \\
\text { Kidney, L HN }\end{array}$ \\
\hline
\end{tabular}

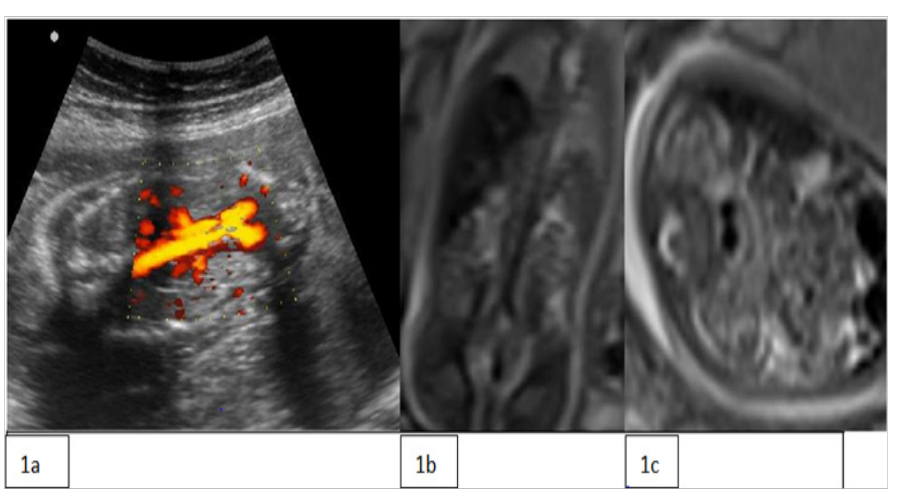

Figure IA CDFU shows renal artery.

IB MRI coronal T2HASTE.

IC Axial T2HASTE reveals non visual kidney at renal fossa.

In normal amniotic fluid group (Table 2) MRI gives additional information in 9 patients, 1 patient with PUJO concordant between USG and MRI. Dilated collecting system is the most frequent cases 
8/10 (80\%) with variation causes: 2 cases due to VUJO, 1 case dilated collecting system due to prune belly sindrom, 1 case due to cloaca malformation, 1 case due to PUJO, 1 case horseshoe kidney, 1 case due to pelvic cyst, 1 case cannot be proved due to stillbirth. Others cases are megacystis microcolon hypoperistaltic syndrome (MMIH) without dilatation of collecting system and 1 cases MCDK of the left kidney.

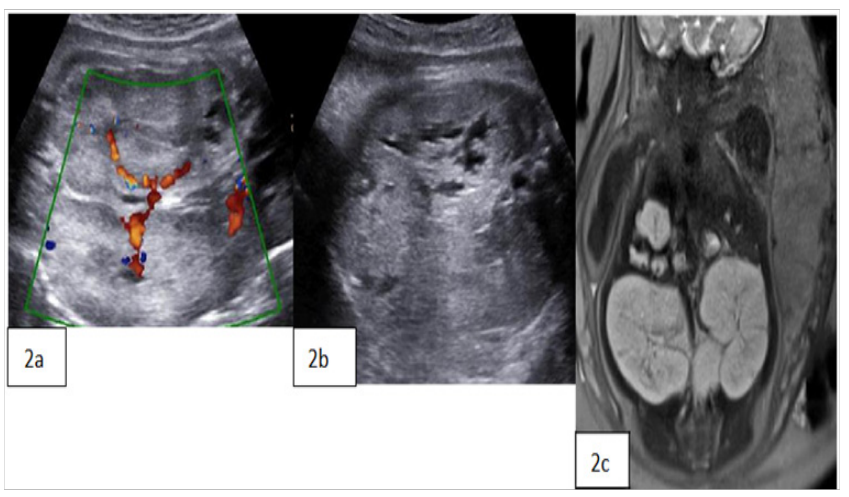

Figure 2A US shows enlarged echogenic medullary with sparing cortex. 2B shows fibrocystic of the liver.

2C Coronal T2HASTE MRI shows hyperintens enlargement both of the kidney and fibrocystic liver. Lung is still hypointens inappropriate with age of gestation. MRI was performed in 35 weeks gestation.

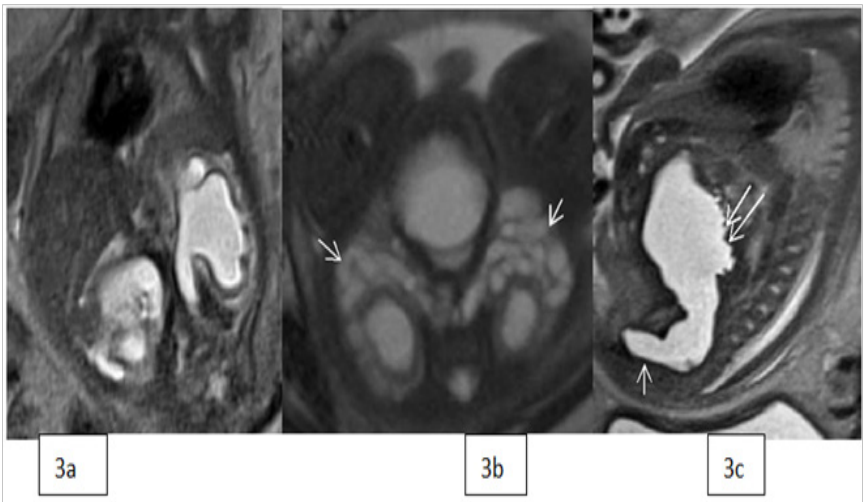

Figure 3A Coronal T2HASTE showing hydroureteronephrosis and thinning renal cortex.

3B Axial T2 bilateral ureter are dilatation (arrow).

3C Showing dilatation anterior urethral (arrow) and irregular posterior wall (double arrow).

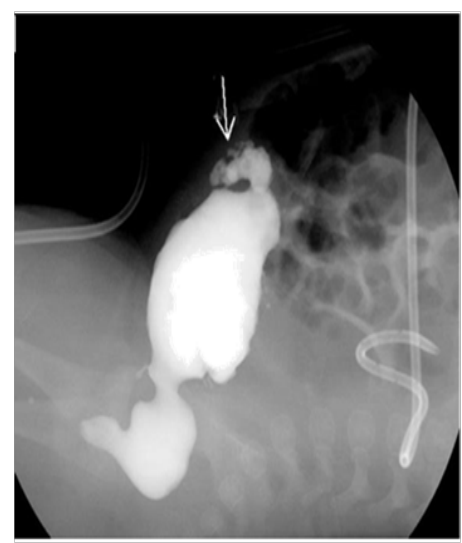

Figure $4 \mathrm{MCU}$ reveals dilatation anterior and posterior urethra and reflux (arrow) and irregular posterior bladder wall.
In case of urinary tract obstruction US has limitation to see the whole length of the ureter for example US was diagnosed hydronephrosis, but MRI hydroureteronephrosis (Figure 5). In massif dilatation and tortuous ureter US has difficulties to differentiate between urinary tract and the bowel (Figure 6). In megacystis cases MRI can give definitive diagnosis as prune belly syndrome (Figure 7) andmmIH (Figure 8). In prune belly MRI reveals bilateral hydrouretronephrosis with cryptorchidism, megacystis with floppy shape bladder wall and dilatation posterior urethra. The floppy shape and absence of bladder wall thickening, cryptorchidism made the working diagnosis is prune belly rather than posterior urethral valve obstruction. MRI can give clear image of the bladder wall compare to US to differentiate between mechanical and functional obstruction. In mechanical obstruction bladder wall is thickened and irregular due to long standing obstruction. InmmIH MRI shows megacystis with dilated stomach, small large bowel and no meconium fills large bowel in female fetus.mmIH is a rare congenital syndrome. It represents severe form of functional obstruction due to abnormal action/myosin resulting hypoperistaltic of the bowel and urinary tract. Ultrasound cannot see the meconium so the diagnosismmIH cannot be established by US.

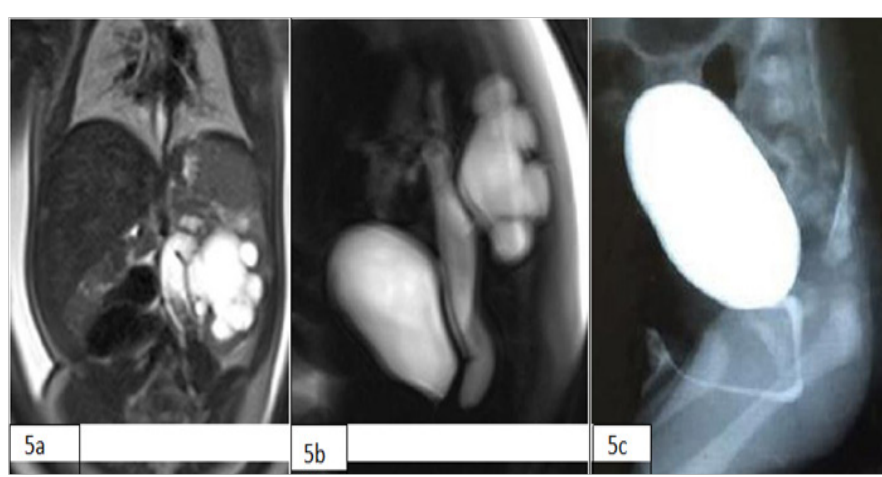

Figure 5A \& B T2HASTE and thick slab MRI showed the whole length ureter and stenosis at $\mathrm{VUJ}$.

$5 \mathrm{CMCU}$ showing no reflux. Final diagnosis VUJO.

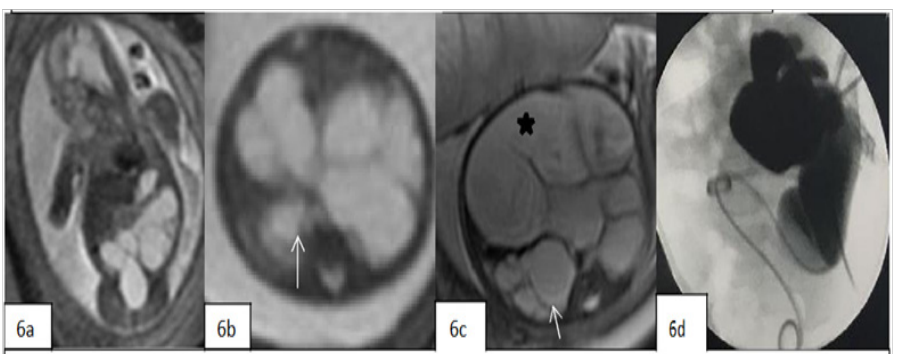

Figure 6A MRI at 19 week gestation, coronal T2 HASTE MRI shows left hydroureteronephrosis.

6B axial MRI shows the right pelviocaliceal dilatation as well (arrow).

6C Follow up MRI at 32 weeks gestation showing right pelviocalyceal dilatation (arrow)and huge left ureter dilatation (asterix).

6D RPG at the left side showing dilatation pelviocaliceal and ureter, no contrast fills bladder.

In multiple pelvic cysts MRI can differentiate between bladder, genital tract and bowel. MRI can determine the level rectal termination which is cannot be seen by US (Figure 9). The depiction of multicystic pelvic mass composed of bladder and hydrometrocolpos, ascites, hydronephrosis and abnormal rectal position should lead to the diagnosis of cloaca malformation. ${ }^{13,14}$ Ascites in this case is due to urine refluxing via fallopian tube. Hydronephrosis is occurred due to bladder obstruction by pouch. Cloacagram with contrast water soluble 
via single opening and colostomy confirm cloaca malformation (Figure 10).

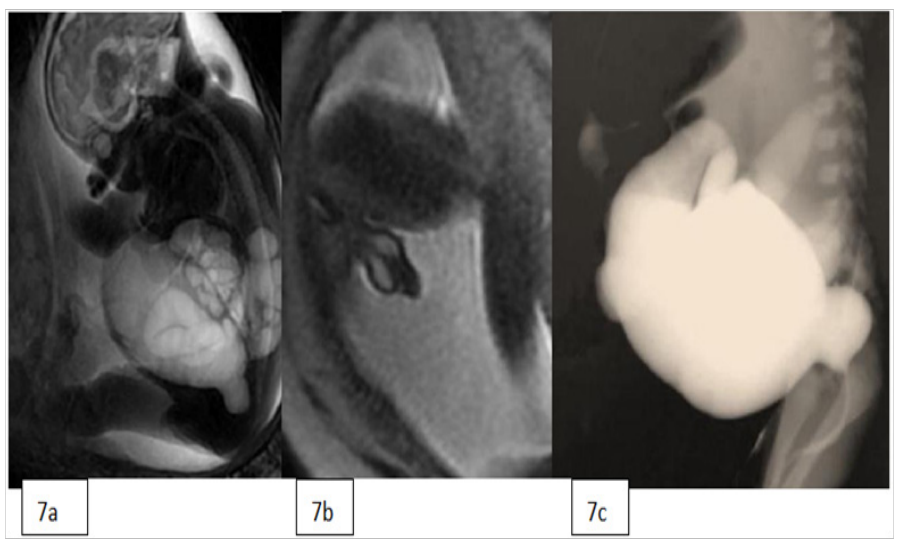

Figure 7A Thick slab MRI showing hydrourtehronpehrosis bilateral, megacystics and dilatation posterior urethra.

7B axial T2HASTE reveals cryptorchidism making the first diagnosis is prune belly.

7C MCU shows reflux contrast grade 4 .

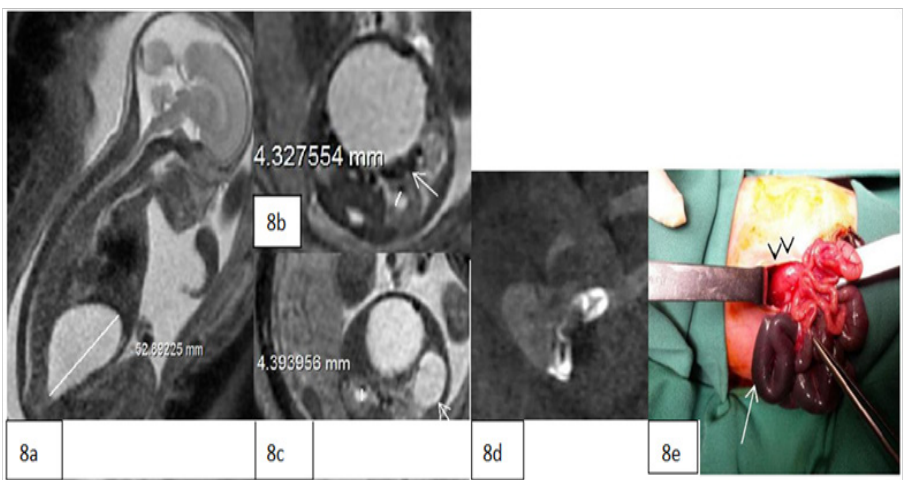

Figure 8A Sagital T2HASTE showing megacystis.

8BAxial T2HASTE shows small colon (arrow).

8C enlargement of stomach (arrow).

8D TISPGR reveals no meconium in colon.

8E Surgical exploration shows malposition microcolon (arrow head), meconium fill small bowel (arrow), no mechanical obstruction.

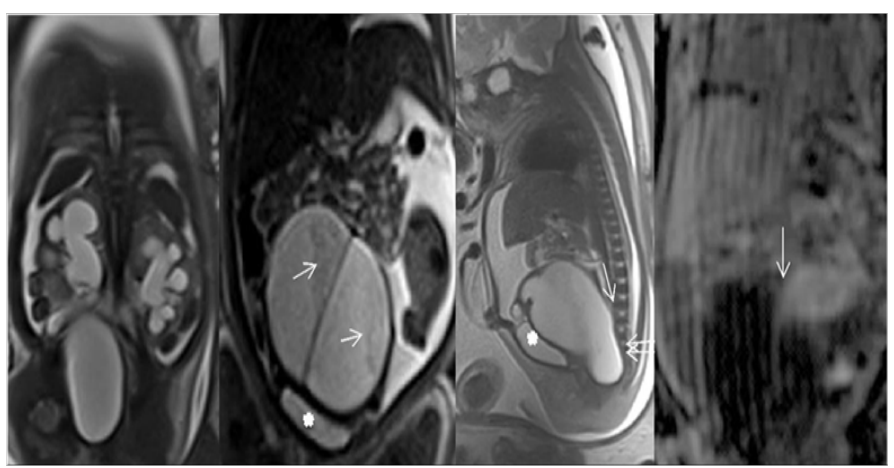

Figure 9A Coronal T2HASTE showing bilateral hydronephrosis and large pouch of vagina.

9B Coronal T2HASTE reveals meconium level in urin containing pouch (arrow), bladder compressed by pouch (star).

9C Sagital T2HASTE Bladder compressed by pouch of hydrometrocolpos, sacral segment present (double arrow), no rectum between pouch and spine. 9D TISPGR shows high rectal termination.

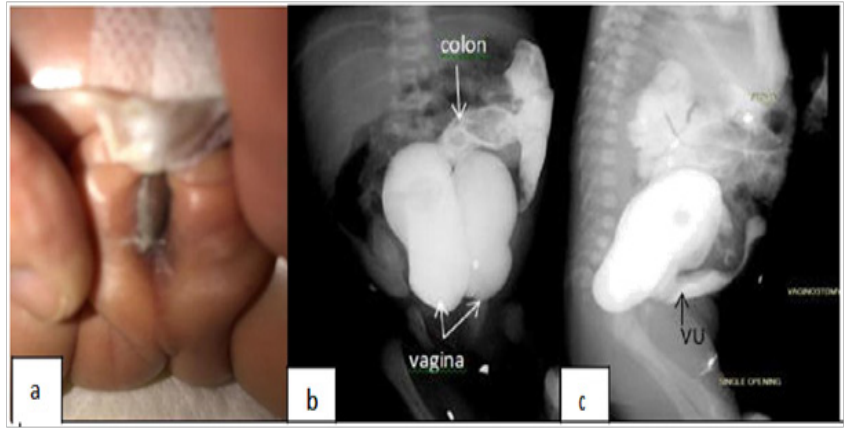

Figure IOA single opening.

IOB Cloacagram shows connection rectum with pouch.

I0C Cloacagram shows connection between vesica urinaria (VU) and pouch.

In left MCDK case US was diagnosed agenesis left kidney due to small field of view (FOV) of the US and the cysts are large enough to occupy the lower abdomen making misdiagnosis as multiple pelvic cyst. Moreover in MCDK there is no normal renal parenchymal can be seen that could make difficulties to determine that the cysts are from the kidney (Figure 11). In megacystic and bilateral hyrourethronepherosis case MRI shows no bladder, right hydronehprosis, left hydrouretronephrosis, ascites and urinoma at the right kidney. Unfortunately the fetus is demised and refused autopsy, but karyotyping result trisomy 13 (Figure 12). In multiple congenital anomalies with improper visualization of kidney MRI can give additional information the shape and dilated pelvicalyceal of the left kidney. These findings are in line with CT finding postpartum (Figure 13).

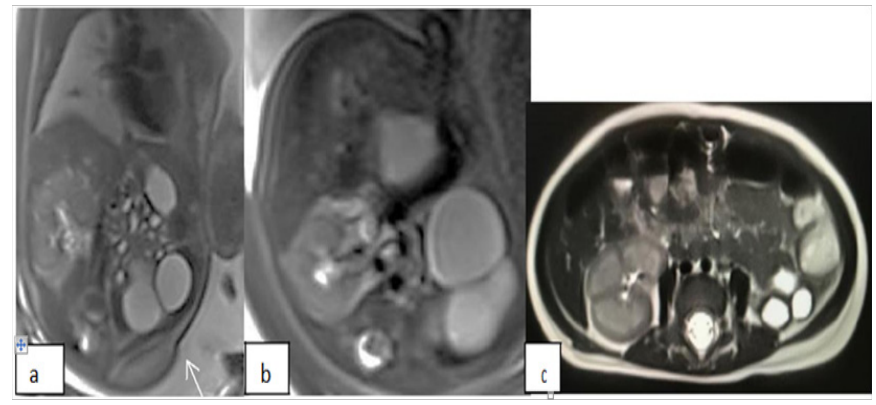

Figure IIA MRI Coronal.

I IB axial T2HASTE reveals multiple variable sized non communicating cysts. I IC Axial T2 HASTE post partum MRI shows L MCDK.

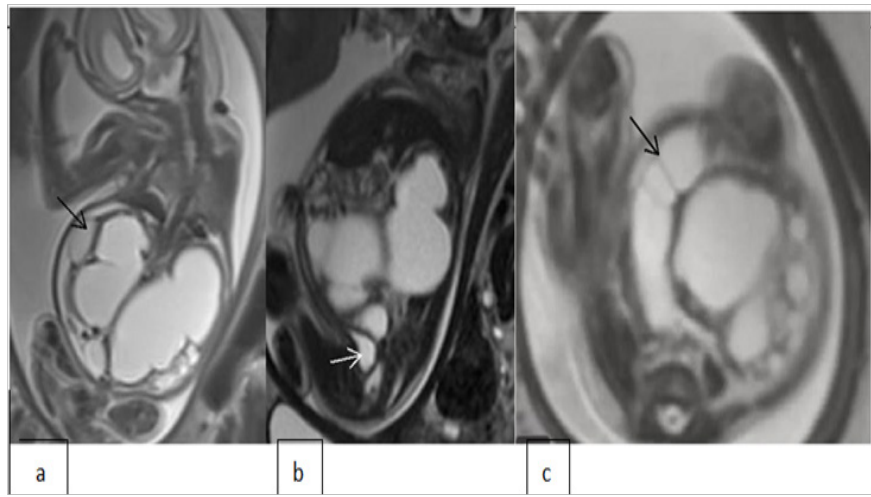

Figure I2A MRIT2 HASTE showing severe hydronephrosis with parenchymal thinning and urinoma (arrow).

I 2B Sagital T2HASTE MRI shows ureterocele (arrow).

I2C axial T2HASTE reveals dilatation of left ureter (arrow) and displastic changes of parenchymal kidney. 


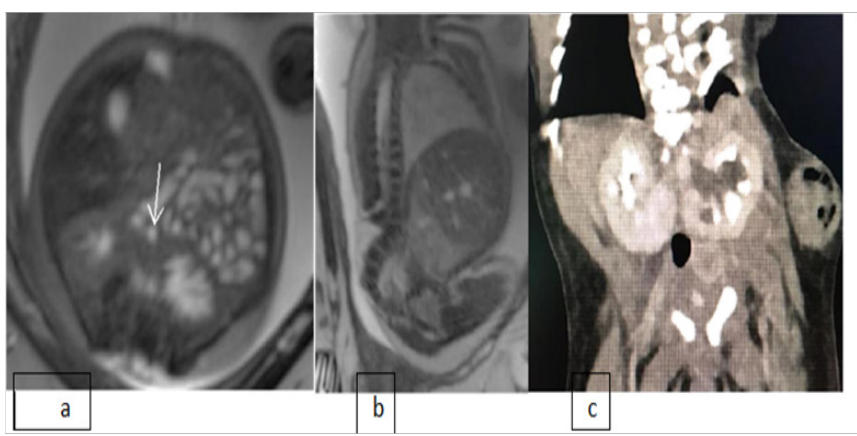

Figure I3A axial T2HASTE shows dilatation pyelocaliceal left kidney and isthmus between right and left kidney (arrow).

I3B Sagital T2MRI shows spinal defect.

I3C CT postpartum showing horsehoe kidney with dilatation of the left pyelocalyceal.

\section{Discussion}

In clinical practice, the ultrasound still the examination of choice for fetal imaging because its availability in health facilities, affordable in financial side and sufficient to answer most of clinical questions. But there are cases with subtle findings on US or clinical problems that US cannot nor hard to give explanation because of the nature of the examination and also because the maternal condition that give not enough windowing for the US. Fetal MRI is one of the advanced imaging that could help and acts as adjunct examination to answer those questions. ${ }^{14}$

Our series found that the MRI on fetal urinary tract anomalies gave a more thorough and detailed anatomy without concerning about abnormally amniotic fluid volume neither (anhydramnios nor oligohydramnios). Even in cases with normal amniotic fluid, fetal MRI is able to give more information regarding the anomalies. With MRI, we can gain findings such as level obstruction in the case of hydronephrosis, the side severity in bilateral involvement of the urinary tract dilatation, association of other anomalies like cryptorchidism, and gastrointestinal abnormalities which contribute in a congenital non syndromic nor syndromic anomalies such asmmIH (gastric dilatation, abnormal passage of the meconium), cloacal malformation, ureterocele, and also gives a clear images regarding anomalies of renal morphology (ie. MCDK, horseshoe kidney) and more detailed anatomy on associated neural tube defect. ${ }^{15,16}$ In cases with extraurinary involvement, MRI can detect intestinal anomalies by visualizing the exact part of the gastrointestinal that has the abnormalities by identifying the distribution of meconium within the bowel and its ability to differentiate between water and meconium. ${ }^{15}$ In our cases with anhydramnios or oligohydramnios, most of the US findings in concordance with the MRI. The superiority of the fetal MR is the ability to see and predict the maturity of the lung parenchyma and lung volume that will affect the patient's pre-and post-treatment. ${ }^{12}$ The additional information provided by MRI will be one from many considerations in the decision of termination choice in cases with severe abnormality that has a high mortality rates. In renal agenesis cases, MR has limitation in differentiating the signal intensity between the kidney and bowel because such cases the renal fossae occupied by the bowel. For that circumstance, the US has advantages with its Doppler ability. Our finding is consistent with Noha et al reported. ${ }^{16}$

The limitation of our studies is small number of fetuses that included in the study. Our fetal MRI cases relatively low since the examination is still new thing for the practicing clinicians, the access to fetal MR facilities is also confined to a very few hospitals, and also very expensive sophisticated examination. The stillbirth cases have no proof since the autopsy is not a compulsory to do in our country.

\section{Conclusion}

Our study shows the capability of MRI to give additional information in fetal urinary tract anomalies both in cases with normal and abnormally low amniotic fluid volume. Prenatal US has limitation due to small field of view, influenced by acoustic windowing, body habitus of the patient and operator dependent. Fetal MRI has the advantage to give detailed anatomy and associated anomalies that change the management of the patient, pre and postnatal.

\section{Acknowledgements}

None.

\section{Conflict of interest}

Author declares that there is no conflict of interest.

\section{References}

1. Toka HR, Toka O, Hariri A, et al. Congenital anomalies of kidney and urinary tract. Seminars in Nephrology. 2010;30(4):374-386.

2. Maria M Rodriguez. Congenital anomalies of the kidney and the urinary tract. Fetal Pediatr Pathol. 2014;33(5-6):293-320.

3. Hindryckx A, De catte L. Prenatal diagnosis of congenital renal and urinary tract malformation. Facts Views Vis Obgyn. 2011;3(3):165-174.

4. Filly RA, Feldstein VA. Fetal genitourinary tract. In: Callen PW, editors. Ultrasonography in obstetrics and gynecology. Philadelphia: Saunders; 2000. p. 515-550.

5. Jaana Poutamo, Ritva Vanninen, Kaarina Partanen, et al. Diagnosing fetal urinary tract abnormalities: benefit of MRI compared to ultrasonography. Acta Obstet Gynecol Scand. 2000;79(1):65-71.

6. Gupta P, Kumar S, Sharma R, et al. The role of magnetic resonance imaging in fetal renal anomalies. Int $J$ Gynaecol Obstet. 2010;111(3):209-212.

7. Caire JT, Ramus RM, Magee KP, et al. MRI of fetal Genitourinary anomalies. AJR. 2003;181(5):1381-1385.

8. Horman M, Brugger PC, Balassy C, et al. Fetal MRI of the urinary system. European Journal of Radiology. 2006;57(2):303-311.

9. Cassart M, Massez A, Metetns T, et al. Complementary role of MRI after sonography in assessing bilateral urinary tract abnormalities in the fetus. AJR Am J Roentgenol. 2004;182(3):689-695.

10. Huppert BJ, Brandt KR, Ramin KD, et al. Single shot fast spin echo MR Imaging of the fetus: a pictorial essay. Radiology Radiographics. 1999;19:S215-S227.

11. Bart RA. Airway Anomalies. In: Fundamental and Advanced Fetal Imaging, US and MRI. In: Kline-Fath BM, editor. Philadelphia: Wolter Kluwer; 2015;17(3):597-616.

12. Balassy C, Kasprian G, Brugger PC, et al. MRI investigation of normal fetal lung maturation using signal intensities on different imaging sequences. Eur Radiol. 2007;17(3):835-842.

13. Chauvin NA, Epelman M, Victoria T, et al. Complex Genitourinary abnormalities on fetal MRI: Imaging findings and approach to diagnosis. AJR Am J Roentgenol. 2012;199(2):222-231.

14. Huertas MG, Casas MC, Garcia FS, et al. Complementary role of magnetic resonance imaging in the study of fetal urinary system. Radiologia. 2016;58(2):101-110 
15. Farhataziz N, Engels JE, Ramus RM, et al. Fetal MRI of urine and meconium by gestational age for the diagnosis of genitourinary and gastrointestinal abnormalities. AJR Am J Roentgenol. 2005;184(6):1891-1897.
16. Noha Hosam El Din Behairy, Lamiaa Adel Salah El Din, Nagla Mohamed Fahmi H, et al. Diagnostic value of fetal MRI in evaluating fetal urinary anomalies. The Egyptian Journal of Radiology and Nuclear Medicine. 2015;46(2):521-528 